\title{
EDUCAÇÃO AMBIENTAL E CULTURA QUILOMBOLA: ENTRE AUSÊNCIAS DE POLÍTICAS PÚBLICAS E PRÁTICAS DE RESISTÊNCIA
}

\author{
Lediane da Silva Borges ${ }^{1}$ \\ João Batista do Carmo Silva² \\ Doriedson do Socorro Rodrigues ${ }^{3}$
}

Resumo: O estudo analisou as relações entre a Educação Ambiental e a cultura quilombola, materializadas em saberes, práticas ambientais e culturais na comunidade Quilombola de Bailique Centro (Oeiras do Pará). Para isso, foi realizada uma pesquisa bibliográfica e de campo, com abordagem qualitativa. A coleta de dados foi mediante entrevistas semiestruturadas. O estudo revelou problemáticas socioambientais, educacionais, de infraestrutura e de saúde, entre outros serviços públicos. Conclui-se que, mesmo com a ausência de políticas públicas educacionais e ambientais, voltadas para sustentabilidade, a materialidade de saberes ambientais está fundada na preocupação da conservação da bio-sócio-diversidade local, explicitada a partir de ações de trabalho, vivenciadas no coletivo.

Palavras-chave: Educação Ambiental; Saberes Ambientais e Culturais; Formação Humana.

Abstract: The study analyzed the relationship between environmental education and quilombola culture, materialized in knowledge, environmental and cultural practices in the Quilombola community of Bailique Centro (Baião-Pará). For this, a bibliographic and field research was carried out, which according to the problem is qualitative, whose data collection was through semi-structured interviews for socio-environmental analysis. The study revealed socio-environmental, educational, infrastructure and health issues, among other public services. It follows that, even with the absence of public educational and environmental policies, focused on sustainability, the materiality of environmental knowledge is based on the concern for the conservation of local biosocio-diversity, made explicit through work actions, experienced in the collective.

Keywords: Environmental Education; Environmental and Cultural Knowledge; Human Formation.

1 Universidade Federal do Pará. E-mail: ledianestumano@gmail.com .

2 Universidade Federal do Pará. E-mail: jbatista@ufpa.br .

3 Universidade Federal do Pará. E-mail: doriedson@ufpa.br .

Revbea, São Paulo, v.16, № 1: 430-449, 2021. 


\section{Introdução}

O presente estudo é um recorte da monografia, apresentada ao curso de Licenciatura em Pedagogia pela Universidade Federal do Pará (UFPA), cuja pesquisa foi realizada com os moradores do povoado quilombola ${ }^{4}$ de Bailique Centro, município de Baião, Estado do Pará, tendo como questão central analisar os saberes ambientais decorrentes das experiências do fazer cotidiano, vinculadas à vida de homens e mulheres quilombolas, expressas em tradições orais e traduzidas nas suas expressões concretas de existência, como afirma Oliveira (2011), em integração com práticas de trabalho que orientam a organização social e os modos de vida de grupos sociais da comunidade quilombola de Bailique Centro (Baião-Pará-Amazônia-Brasil), problematizando-se as relações que estabelecem com esses saberes, como são constituídos e desenvolvidos na comunidade.

O espaço físico social, onde foi realizada a pesquisa, centra-se na comunidade remanescente quilombola de Bailique Centro, localizado nas proximidades do $\mathrm{km} 83$ da $\mathrm{Br}$. 422, à margem direita do rio Tocantins, entre os municípios de Oeiras do Pará e Baião-PA, área quilombola, que faz parte do território rural intitulado e reconhecido pelo Instituto de Terras do Pará (ITERPA) como Associação de Remanescentes de Quilombos de Bailique (ARQBI), para ocupação e uso das famílias remanescente de quilombos da comunidade Bailique, com área total de $2.000 \mathrm{~m}^{2}$ (ITERPA, 2002).

O acesso à comunidade é por via terrestre ou fluvial, pela BR 422, estrada de chão batido e pelo Rio Tocantins que liga vários Municípios, entre eles, Baião. Assim, podemos traçar a trajetória do Município de Cametá à comunidade de Bailique Centro, percorrendo $83 \mathrm{~km}$ de estrada de chão, e adentrando-se ao lado esquerdo ao ramal, percorrendo, desse modo, mais $1,300 \mathrm{~km}$, para enfim chegar a área de estudo, totalizando uma trajetória de 84, $300 \mathrm{~km}$.

Nas Figuras 1 a 3 identificamos a rota utilizada para o deslocamento da cidade de Cametá e de Baião até o lócus de pesquisa, bem como a área estudada e a rua principal da comunidade, tendo como ponto de referência a escola e as residências dos nove moradores, entre mulheres e homens, intérpretes desta pesquisa.

\footnotetext{
4 Segundo afirma Pinto (2010), quilombola diz respeito à povoação (ou habitante desta), originária de antigo reduto de negros fugitivos, os resistentes do processo escravistas. A autora também ressalta que, de origem Kimbundo (Sul de Angola), as palavras quilombo e mocambo têm significados diferentes.
} 


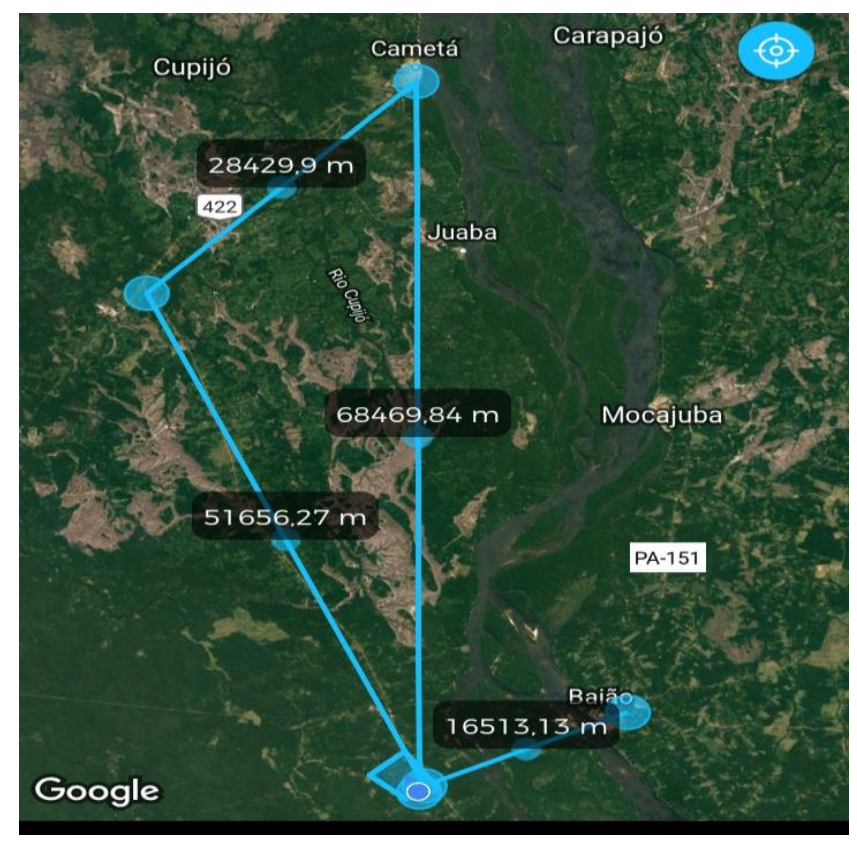

Figura 1: Mapa da trajetória do Município de Cametá e Baião até o lócus da pesquisa. Fonte: Elaborado pelos próprios autores (2020).

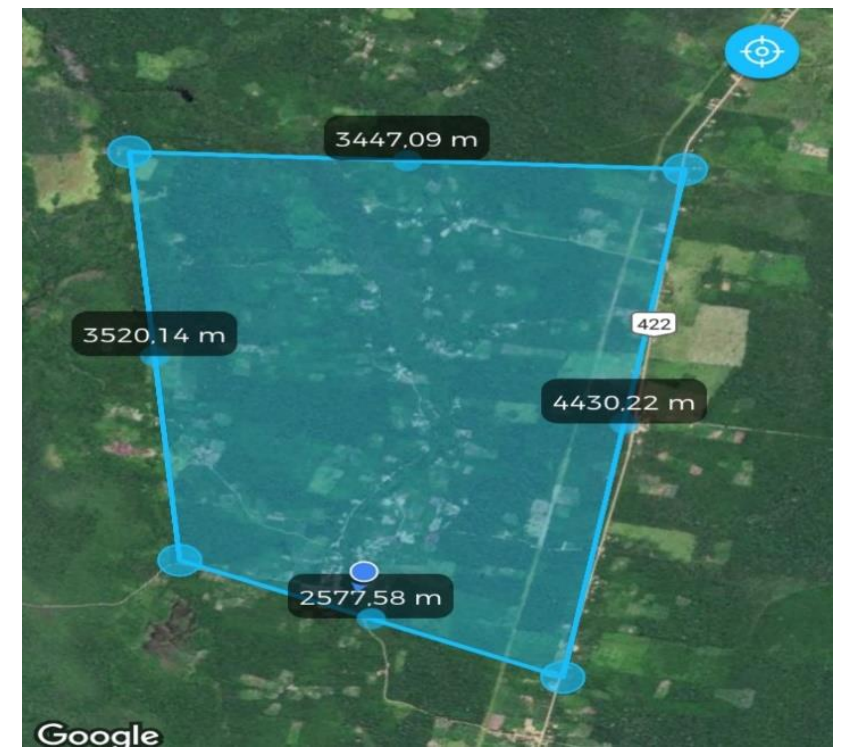

Figura 2: Delimitação Empírica da área de estudo. Fonte: Elaborado pelos próprios autores (2020). 


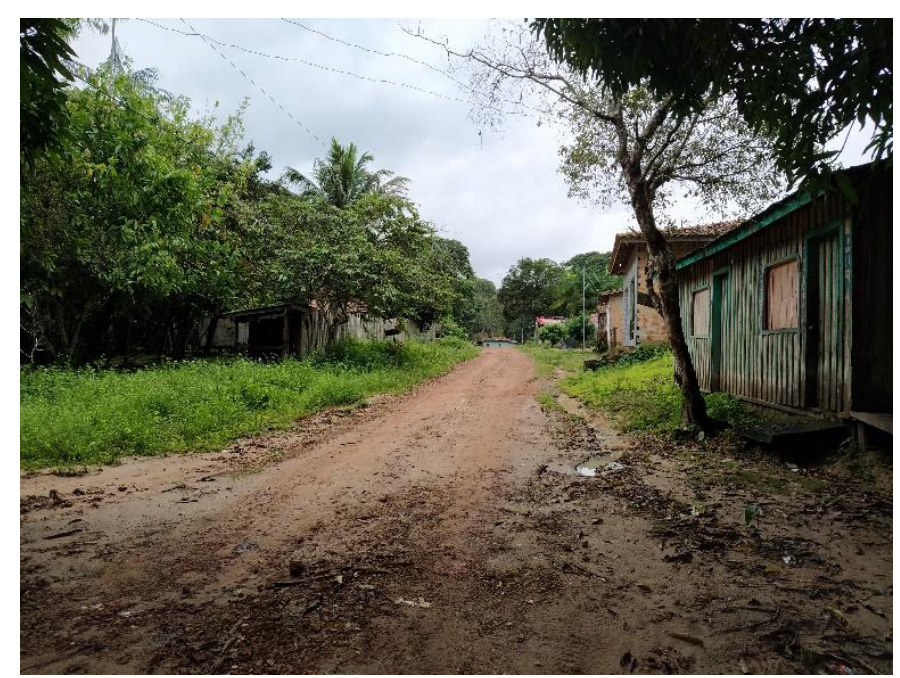

Figura 3: Rua de acesso principal da comunidade de Bailique Centro.

Fonte: Elaborado pelos próprios autores (2020).

Este estudo, baseado em pesquisas sobre o mote em tela e nas narrativas dos sujeitos da pesquisa, teve como objetivo analisar as relações entre a Educação Ambiental e a cultura quilombola, materializadas em saberes, práticas ambientais e culturais na comunidade Quilombola de Bailique Centro (Oeiras do Pará).

Os processos metodológicos foram estabelecidos a partir de diálogos com autores, que se ocupam da temática em estudo, como: Leff (2001), Tuan (1980), Laraia (2009), além de outros que auxiliaram nas análises da sua constituição. Da mesma forma, realizamos a pesquisa de campo, a partir da observação no lócus, cujo instrumento de coletas de dados utilizado foram as entrevistas semiestruturadas com análise socioambiental.

Optamos por uma investigação qualitativa, esta que, segundo Araujo (2012), possibilita observar, registrar e analisar as narrativas dos moradores, as relações sócio-culturais-ambientais e de trabalho da comunidade pesquisada, procedendo, em seguida, a uma etnografia da vida dos seus sujeitos com suas experiências cotidianas, os procedimentos, as atitudes e os valores das pessoas, conforme Godoy (1995).

Para isso, contamos com a colaboração de 06 (seis) sujeitos entre homens e mulheres, na faixa etária de 35 a 81 anos que explicitam, em suas narrativas, saberes e práticas ambientais, sendo os dados analisados na correlação entre desafios a enfrentar pela comunidade no que concerne às práticas cultural e ambiental e a presença/ausência de políticas públicas nessa perspectiva, observando-se a Educação Ambiental, suas potencialidades e limites nos diálogos com os povos e comunidades tradicionais afro-brasileiras, a partir de Bailique-Pará. Optamos também por manter somente a inicial da letra do nome dos sujeitos, visto que eles preferem se identificar dessa maneira, para os propósitos da presente pesquisa. 
Destacamos que, para uma percepção do cotidiano, da cultura e das tradições da população quilombola em estudo, foi necessário estabelecer um relacionamento com alguns sujeitos da comunidade, a fim de favorecer o acesso às histórias de vida e às suas experiências no dia a dia, analisando como os saberes e os fazeres dos remanescentes quilombolas dialogam com a Educação Ambiental, a partir das "Histórias de Vida".

Na comunidade Quilombola de Bailique Centro, a maioria dos moradores vive da caça, pesca e em específico da agricultura familiar, precisamente da roça na produção de farinha, milho e arroz e das criações de animais e cultivo dos vegetais, sendo que a base da economia é a produção agrícola de subsistência. Além disso, recebem apoio de programas sociais, como o Bolsa Família.

A comunidade apresenta, também, traços culturais afro-brasileiros, herdados pelos primeiros moradores, cujos costumes, valores, respeito, valorização do ambiente, crenças, danças, comidas, linguagem, lendas, artesanatos e outras estão gravadas na memória como forma de simbologia e valorização cultural e constantemente sendo repassadas às novas gerações, legado de um longo processo acumulativo que reflete o conhecimento e a experiência, resultando no esforço da comunidade, como assevera Laraia (2009).

A realidade rural quilombola de Bailique Centro é marcada pela precariedade social, econômica e política. Contudo, mesmo com as dificuldades existentes, têm-se garantido sustentavelmente os recursos da natureza e o desenvolvimento da Educação Ambiental no território, visto que essas comunidades quilombolas, de acordo com Shiva (2003, p. 22): "[...] criaram uma forma de saber e descobriram maneiras de tirar seu sustento da natureza" mesmo enfrentando problemáticas socioambientais de infraestrutura, tais como: falta de saneamento básico e de água tratada, atendimento de saúde precários e insuficientes, falta de coleta de resíduo sólido e outras suas práticas de trabalho e organização social são pensadas nas preocupações de conservação da bio-sócio-diversidade local.

As crianças, assim como os jovens, aprendem desde cedo algumas práticas de agricultura e cuidados com o ambiente, como: adubar a terra com restos de materiais orgânicos da natureza, plantar e colher em tempos determinados, cuidar do solo e água etc.; é uma "[...] rede de saberes quilombolas que não se reconhece em teoria senão em prática através do trabalho, pela agricultura, pela convivência diária", como ressalta Muñoz (2003, p. 14).

O dia todo, os moradores mantêm o contato direto com o ambiente. Quando não estão na lavoura, estão no quintal cuidando dos animais, plantas, varrendo terreiro, capinando, colhendo milho, arroz ou coletando produtos do mato, fazendo remédios ou alguma alimentação que vem da própria natureza.

Com base no exposto, além dessa Introdução, este artigo organiza-se em quatro seções, descritas a seguir:

Revbea, São Paulo, v.16, № 1: 430-449, 2021. 
$\mathrm{Na}$ primeira, discutimos aspectos teóricos de Educação Ambiental em interação com elementos de Cultura Quilombola; na segunda, abordamos os saberes ambientais em Comunidades Quilombolas; na terceira, explicitamos como se Constituem e Expressam os Saberes Culturais e Ambientais; e na quarta, problematizamos esses Saberes Ambientais com as lutas e as práticas de resistências da Comunidade Quilombola de Bailique Centro, Oeiras do Pará-PA.

Após essas discussões, temos as Considerações Finais e, por fim, Referências, nas quais são informadas as fontes de consulta utilizadas para 0 aporte teórico desta pesquisa.

\section{Educação Ambiental e Cultura Quilombola}

A Educação Ambiental e Cultura Quilombola nas comunidades tradicionais não se concretizam sem o reconhecimento da realidade histórica dos sujeitos que nela vivem. Por isso, identificar seus processos culturais, sua socialização e as relações de trabalho, vividas pelos sujeitos em suas práticas diárias, implica reconhecer, nesse sentido, que a Educação Ambiental e a Cultura Quilombola favorecem a identidade de uma comunidade e o reconhecimento de diferentes saberes e fazeres já construídos, a partir de suas histórias de vida.

A perspectiva ambiental consiste num modo de perceber o mundo como ele está evidenciado em vários elementos para a constituição e manutenção da vida, pois, à medida que o indivíduo intervém na natureza, em busca de satisfazer sua necessidade, surgem tensões, agressões e produções ao ambiente natural. "O ambiente não é o meio que circunda a espécie e as populações biológicas é uma categoria sociológica relativa a uma racionalidade social, configurada por comportamento, valores e saberes" (LEFF, 2010, p.160).

Essa relação humano-natureza vai além de compreender a biodiversidade, é o que afirma Leff (2010), visto que há necessidade de o indivíduo manter a relação social entre os seres vivos e o ambiente por intermédio da sociologia do conhecimento que 'abre' um campo de estudo a respeito da condição ambiental (ecológicas e sociais) que induz a produção e a transformação do conhecimento ambiental.

A relação do humano-natureza já vem sendo desenvolvida historicamente, uma vez que não se pode pensar Educação Ambiental sem pensar na ação humana sobre a natureza. E esta ação pode ser vista de duas formas: uma coletiva e outra transformadora (modificar), como específica Charlot e Silva (2005, p. 66): "[...] Não se pode, pois, pensar separadamente a natureza, a organização social, o tipo de indivíduo que existe em um dado momento da história". 
Infelizmente, muitos confundem a relação do homem-natureza com as relações sociais dos homens entre si. A natureza não é objeto eterno e imutável, situação observada por meio do resultado da ação coletiva de transformação do mundo pelo homem. Segundo Laraia (2009, p. 24),

O homem é o resultado do meio cultural em que foi socializado. Ele é um herdeiro de um longo processo acumulativo, que reflete $o$ conhecimento e a experiência adquirida pelas numerosas gerações que 0 antecederam. A manipulação adequada e criativa desse patrimônio cultural permite as inovações e as invenções. Estas não são, pois, o produto da ação isolada de um gênio, mas o resultado do esforço de toda uma comunidade.

Na perspectiva cultural, o termo cultura já vem sendo evidenciado por diversos autores, ao longo da história da humanidade, com definições bastante distintas, sendo, desse modo, um termo amplo. A cultura pode ter sentido como questão de poder, no processo de competição e do conflito ou considerada como símbolo por causa dos sentimentos, sentidos, de significado que esta tem de um determinado povo. Como questão de poder pelo simples fato de que o ser humano exerce uma forma de interesse próprio por meio da cultura.

\section{Saberes Ambientais em Comunidades Quilombolas}

Os povos quilombolas historicamente desenvolveram suas culturas em profunda relação com o ambiente natural. Entretanto, pouco se sabe sobre o papel dos elementos da natureza na formação desses povos e na construção de seus saberes tradicionais. De acordo com a recomendação da Convenção sobre a Diversidade Biológica, os saberes tradicionais devem ser reconhecidos, respeitados, mantidos e preservados para a conservação e o uso sustentado da diversidade biológica (MMA, 1998). Entendemos, assim, que a sobrevivência desses povos e a própria conservação da biodiversidade dependem da recuperação desses saberes que, aliados às novas tecnologias, devem garantir os projetos das comunidades tradicionais.

Nessa proposta, os saberes tradicionais tornam-se fundamentais para as novas gerações de quilombolas e para a construção de um diálogo de saberes que, na concepção de Leff (2006), implica na apropriação de conhecimentos e saberes de diferentes racionalidades culturais e identidades étnicas, produzindo novas significações sociais, novas formas de subjetividade e posicionamentos políticos em relação ao mundo.

O diálogo de saberes nasce no encontro de identidades. O ser, além de sua condição existencial geral e genérica, diferencia-se em identidades coletivas que se constituem na diversidade cultural e em uma política da diferença, mobilizando os atores sociais para a construção de alternativas de 
reapropriação da natureza em um campo conflitivo de poder, onde se desenvolvem sentidos diferenciados, muitas vezes antagônicos, de projetos políticos para a construção de um futuro sustentável, como afiança Leff (2006).

A relação do ser humano com o real é caracterizada por sua intermediação por intermédio do saber. Para Leff (2006), a história é produto da intervenção do pensamento no mundo, não obra da natureza. $O$ autor defende o que intitula "saber ambiental" como a visão sujeito e objeto do conhecimento, quando reconhece as potencialidades do real e incorpora identidades e valores culturais.

A importância da Educação Ambiental como uma dimensão essencial do A importância da Educação Ambiental como uma dimensão essencial do processo pedagógico, situa-se no centro do projeto educativo de desenvolvimento do ser humano, enquanto ser da natureza, conforme sugestão de Carlos Frederico Loureiro (2004).

Assim, pensando a realidade da população quilombola de Bailique Centro, diante do quadro de degradação socioambiental expresso na atualidade, acreditamos que os fundamentos da Educação Ambiental possam contribuir com uma ação educativa, emancipatória e transformadora, favorecendo e potencializando a autonomia no propósito de melhorar as condições de vida de seu povo e, dessa maneira, apostar na força de uma educação também ambiental, engajada, séria e verdadeira.

Para isso, foi pensado um processo pedagógico que se desenvolve a partir da realidade e do cotidiano quilombola, valorizando os saberes ambientais, conduzindo os alunos e a comunidade à compreensão complexa e integrada do ambiente, a fim de estabelecer, como desafio para a educação quilombola, uma efetiva aproximação aos significados sobre ambiente e natureza, próprios dos quilombolas. Tal conquista revelaria o reconhecimento da pluralidade e diversidade, da valorização e sistematização dos conhecimentos tradicionais, da organização social, de suas formas de representação de mundo.

A escola deve ser um espaço que oportuniza o diálogo com os "conhecimentos universais" ou dialoga com os "outros" saberes, nesse caso, os ambientais na própria comunidade quilombola, tendo como horizonte a vivência de uma pedagogia intercultural. Logo, com o propósito de uma educação quilombola, as leituras de ambiente apresentam-se significativas para propor o currículo.

\section{Os Saberes Ambientais e a Educação Ambiental em Comunidades Quilombolas}

A Educação está presente no cotidiano do Quilombo de várias maneiras, visto que a relação da Educação com a Educação Ambiental se encontra na comunidade, tanto no modo formal quanto no informal. As rotinas das famílias 
na comunidade apresentam simbologias que auxiliam na conservação dos fazeres que as identificam.

A riqueza de saberes é construída coletivamente, falam sobre as formas de vida, os ciclos naturais, o clima, a vegetação, entre outros elementos; é parte da vida das pessoas que ali vivem e conhecem sobre a comunidade; é essa riqueza de saberes que age no uso e na manutenção da biodiversidade do local. Esses saberes são também os caminhos para a práxis de Educação Ambiental nas comunidades quilombolas, tendo esses conhecimentos como ferramentas pedagógicas que podem auxiliar a relação educativo Ambiental.

As comunidades, que reconhecem a sua cultura e preservam os seus costumes como uma riqueza de seu povo, sabem usar os seus saberes a favor de todos. Para Leff (2001, p. 145):

O saber ambiental excede as "ciências ambientais", constituídas como um conjunto de especializações surgidas da incorporação dos enfoques ecológicos às disciplinas tradicionais - antropologia ecológica, ecologia urbana, saúde, psicologia, economia e engenharia ambientais - e se estende além do campo de articulação das ciências, para abrir-se ao terreno dos valores éticos, dos conhecimentos práticos e dos saberes tradicionais.

O saber Ambiental, alcançado pelo uso da interdisciplinaridade, pode proporcionar várias opções de análise do uso desses saberes tanto pela comunidade quanto pelos estudiosos.

Santos (2008) afirma que os grupos sociais tradicionais têm seu dinamismo e tempos próprios: observação, oralidade, experiência íntima e mítica com o espaço vivido e relações de trabalho são vivenciadas em círculos familiares e de amizade. A hipótese inicial é a de que os saberes ecológicos são repassados intergeracionalmente e são usados como ferramentas de Educação Ambiental pelas novas gerações do quilombo. Para tanto, acreditase que a capacidade de aprender, com a própria vivência, vem de experiências vividas "do" e "no" espaço do quilombo.

Tuan (1980) enfatiza que os valores e as atitudes se relacionam com as necessidades biológicas, à cultura e com os valores pessoais, estabelecidos na interação com a sociedade. Isso sugere afirmar que a relação humana com o meio ambiente deve ser vista por meio de uma perspectiva não somente social, e sim também ecológica e temporal. Isso é o que se pretende ao analisarmos a transmissão dos conhecimentos adquiridos ao longo da vida pelos idosos para os mais jovens na comunidade do Quilombo de Bailique Centro.

Ao se tratar dos sistemas de manejos dos recursos naturais, as comunidades quilombolas têm se preocupado em respeitar o ciclo da natureza como plantar e colher no tempo correto e reutilizar os próprios recursos que a 
natureza fornece, realizando, desse modo, as técnicas de compostagens e adubação. Os sistemas de manejos, principalmente na agricultura da mandioca, açaí e pimenta do reino, têm garantido, sustentavelmente, os recursos da localidade, nesse caso, a comunidade de Bailique Centro pesquisada; a natureza por si só faz o seu ciclo e os moradores esperam esse processo, a fim de preservar e cuidar da mata.

Geralmente, os moradores adubam as terras com a própria roçagem feita ou com restos de vegetais (materiais orgânicos da natureza, por exemplo: mato, pau podre) e animais mortos na região. Esses manejos ou técnicas, feitas pelos moradores, mostram-nos um conjunto de saberes e conhecimentos desenvolvidos e herdados pelos quilombolas da localidade.

Portanto, os saberes ambientais, nas comunidades quilombolas, têm influenciado na preservação do meio ambiente, principalmente da localidade pesquisada, onde tentamos assimilar o valor dos saberes desenvolvidos pelos moradores para a sensibilização em Educação Ambiental.

O saber aqui analisado é justamente relacionado com a identidade dos moradores de Bailique Centro, uma vez que esses saberes se refletem por meio dos bens imateriais, como: os conhecimentos, os valores, as habilidades, os saberes que, com a produção dos bens materiais, surgem. Por conseguinte, esse tipo de saber é o resultado do trabalho humano e do contexto histórico social, favorecendo as habilidades, os valores, as atitudes e as posturas que, voltados para prática, possibilitam o aprendizado de novas técnicas do aprender-fazendo.

Contudo, esses saberes são caminhos para o desenvolvimento da Educação Ambiental nas comunidades quilombolas, considerando esses conhecimentos como ferramentas pedagógicas que podem auxiliar a relação educativo- ambiental. Assim, observamos a importância da Educação Ambiental como uma dimensão do processo pedagógico para 0 desenvolvimento do ser humano. A partir da análise da população quilombola de Bailique Centro, acreditamos que essa dimensão possa contribuir para uma ação educativa e transformadora para, desse modo, apostar numa Educação Ambiental, engajada, séria e verdadeira.

\section{Como se Constituem e Expressam os Saberes Culturais e Ambientais}

Alguns moradores já vêm realizando, há bastante tempo, a prática da agricultura familiar. Muitos plantam verduras, legumes, frutas, mandioca, milho, arroz, pimenta do reino etc.; realizam as técnicas da compostagem em suas casas ou nas roças e reutilizam os restos de recursos naturais, como: folhas, terra preta, resto de animais mortos nos pés das plantações, respeitam o período de reproduções das plantas e animais. Passaram também a criar animais, como: galinha, porco, peru, pato etc. e reutilizar suas fezes e moinha para compostagem. 
Notamos que esses saberes são construídos com base na vivência da comunidade e isso prioriza a integração do homem e da natureza, garantindo um saber ambiental que, embora muitas pessoas da comunidade não compreendam cientificamente, os desenvolvem, conforme Berger Filho e Sparemberger (2008, s/p) afirmam que "[...] esses conhecimentos aparecem no cotidiano através de ações de caráter religioso, material e conhecimento do ciclo de vida com caráter holístico, animista, que prioriza a integração equilibrada do homem e da natureza".

Observamos nas falas da moradora "M" (38 anos): "[...] aqui em casa nós planta de tudo e recada resto de alimentos, pau seco, folha e põe nas plantas é o melhor adubo". Ao invés de comprarem produtos químicos, eles utilizam os restos de vegetais e animais misturados com terra preta (húmus) e colocam nas plantações, realizando o manejo sustentável na agricultura, respeitando o período da colheita e o clima da região. Isso, além de ser uma maneira sustentável para contribuir com o ambiente, garante também o consumo diário das famílias (renda e alimentação) e valoriza os saberes ambientais.

As técnicas de preparo da terra vêm sendo desenvolvida, há bastante tempo e repassadas a novas gerações, como afirma morador "P" (79 anos): "[...] Eu aprendi assim e ensinei meus filhos; a gente usa o que tem na mata. Hoje em dia, dona, que muitos não querem fazer isso, preferem comprar e muitos têm preguiça de colher o que a nossa natureza dá".

Quando os moradores pretendem plantar, geralmente, eles preparam o solo com os recursos da natureza com técnicas de adubação e de compostagem, esperando determinado período para que o solo esteja completamente pronto $e$, desse modo, podem realizar o plantio e, posteriormente, com o tempo, a colheita. O plantio, caso seja pequeno, eles acontecem ao redor das casas; e se forem grandes são realizados em áreas separadas, chamadas roças. Embora os moradores não percebam cientificamente sobre o saber ambiental, eles o executam em sua prática diária. Autores, como Leff (2006), defendem esses conhecimentos dos povos quilombolas como um saber quando são reconhecidas as potencialidades do real e incorporadas identidades e valores culturais.

As plantações de grande produção são as da mandioca para a produção de farinha, da pimenta do reino e do açaí. Todas essas plantações requerem um preparo e um manejo no solo e esses saberes ambientais são práticas diárias das famílias que adquirem esses conhecimentos de seus antepassados, visto que não recebem ajuda de técnicos e engenheiro agrônomo. Sempre há um cuidado com o solo, geralmente é capinado o terreno e reutilizados os restos de recursos naturais do próprio solo como adubo orgânico.

No campo da agroecologia, as plantas leguminosas, como o feijão, fazem a adubação verde. Estas, quando plantadas junto a outra espécie, fertilizam o solo. A tradição de plantio de mandioca se associou com milho ou arroz no plantio de feijão e de maxixe. Nesse encontro, construíram novas 
significações e práticas sociais, a partir de premissas comuns: complexidade e magia das plantas. A comunidade realiza a prática e o plantio das leguminosas devido à experiência repassada pelos antepassados sem compreenderem o saber ambiental que, conseguido pela interdisciplinaridade, pode proporcionar uma análise desses saberes tanto pela comunidade quanto pelos estudiosos.

Nos quintais ou terreno dos moradores, além das plantas frutíferas e das grandes colheitas, veem-se também o plantio de plantas medicinais, como: boldo, jucá, urtiga, quebra pedra, erva cidreira, canela, gengibre, pata de vaca, terramicina, mastruz, unha do gato, pau pereira, barbatimão, pau verônica etc.

Plantas que têm efeito cicatrizantes e anestésico, servindo para curar dores e problemas no fígado, estômago, diabetes etc.; e são usadas diariamente pelos moradores, substituindo os medicamentos farmacêuticos. Os moradores utilizam as plantas medicinais como plantas curativas e esse saber sobre as plantas tem sido repassado às novas gerações que alegam ser melhores que os medicamentos farmacêuticos, como afirmado nas falas dos moradores.

Esses conhecimentos das plantas medicinais vêm sendo repassados de geração a geração como forma de um saber ambiental. A comunidade local reconhece a sua cultura; preserva os seus costumes como uma riqueza de seu povo; e sabe usar os seus saberes a favor de todos.

As igrejas da localidade também falam em resgatar os saberes culturais e ambientais dos seus antepassados principalmente para os jovens, adolescente e crianças, o que reforça a identidade do morador e o compromisso social e ambiental. Assim, é reafirmado que, por meio da Educação, é possível criar sujeitos críticos, autônomos, participativos e emancipados, de acordo com Amorim (2005).

Por intermédio das danças que ainda acontecem na comunidade, como feijoada, farinhada, samba de cacete, quadrilhas, notamos 0 desenvolvimento dos saberes culturais com elementos ambientais.

Outra forma de notar os saberes ambientais, desenvolvidos pela comunidade, é quanto aos traços na alimentação dos moradores, como a farinha, tapioca, tucupi, milho, arroz, feijão, carne seca, peixe seco, xibé (água e farinha), verduras e frutas, herdadas e cultivadas pelos seus antepassados, que são comidas e têm grandes valores, repassados de geração a geração como uma das formas de repassar o conhecimento cultural e ambiental.

Para compreender a respeito da constituição dos saberes ambientais na comunidade quilombola de Bailique Centro, analisamos como os seus costumes, crenças, valores, ensinamentos, termos simbólicos da cultura local, podem manter o saber ambiental, desenvolvido pelos moradores ao longo da história da comunidade.

Nas entrevistas, os diálogos consistiram em como era e como é o ambiente natural e qual o grau de diversidade viva (natural e cultural). A 
maioria dos entrevistados relata que há 50 anos havia bastantes animais e plantas, rios e igarapés; uma vegetação preservada, baseada no princípio da sustentabilidade e que, atualmente, algumas famílias infelizmente têm pouco se preocupado com a preservação natural e cultural.

Inferimos nas repostas dos moradores quanto à noção de pertencimento e a relação que estes têm com o ambiente, visto que a maioria, ainda, utiliza e preserva os recursos da natureza, acreditando no princípio de depender e se relacionar com o sagrado e o natural.

Ao perguntar sobre agricultura familiar e sua prática diária, a maioria dos entrevistados alega realizar tal prática por esta ser a base da sustentação familiar.

Ao perguntar sobre a questão dos resíduos sólidos, a maioria dos entrevistados alega que os moradores não estão preocupados, não se tem o cuidado com seu destino, com a noção de consumismo e muito menos com os problemas ambientais. Enquanto a minoria acredita que queimar e enterrar é a solução.

Em uma das entrevistas, notamos que a maioria dos entrevistados não conhece a Lei da Educação Ambiental. Mesmo que a maior parte dos entrevistados não conheça de fato a Lei sobre a Educação Ambiental, eles, em sua prática diária, são orientados para conservarem a bio-sócio-diversidade local.

Devido à importância da cultura e do ambiente, constatamos uma relação com o que eles acreditam ser sagrados, por pertencerem ao ambiente e dependerem totalmente da natureza. E essa relação com o ambiente é cotidiana, portanto, o convívio com as plantas e outros elementos da natureza é observado na prática e nas falas da maioria dos entrevistados. Assim, cotidianamente os moradores realizam práticas de adubação, técnica de compostagem, práticas com agricultura familiar e manejos sustentáveis.

Ao falar nas entrevistas sobre a valorização da biodiversidade na localidade, todos os colaboradores relataram que existe uma profunda relação com as plantas, visto que esses saberes ambientais sobre as plantas, a relação com o ambiente e as questões dos problemas ambientais são repassadas pelos antigos moradores, além de serem discutidas em reuniões da associação da comunidade e pelas igrejas do local.

Quanto à questão da água e do solo da região, a metade dos entrevistados alega que cuida e preserva, de forma sustentável, os recursos da natureza.

Após analisar o ambiente, perguntamos para os entrevistados sobre questões como infraestrutura, saneamento básico, água tratada e assistência em saúde: todos os sujeitos contam que na comunidade não se contemplam essas questões devido, não existirem políticas públicas para a localidade.

Observamos que, mesmo que a comunidade esteja enfrentando 
problemáticas socioambientais de infraestrutura, como a inexistência de saneamento básico e de água tratada; a falta da coleta dos resíduos sólidos; o acesso e 0 atendimento de saúde são precários e insuficientes e/ou inexistência assistência técnica, entre outras dificuldades que venham interferir politicamente e socialmente, além da necessária melhoria da qualidade de vida e das condições ambientais, ainda assim suas práticas de trabalho e organização social são orientadas por preocupações de conservação da biosócio-diversidade local por meio da agricultura familiar e de seus manejos, além dos desenvolvimentos de projetos.

O desenvolvimento dos projetos e da prática de organização de trabalho, como a agricultura familiar e seus manejos, contribuem economicamente para a região, uma vez que, além dos moradores garantirem um equilíbrio ambiental e um ambiente sustentável, a comunidade pode desenvolver os saberes culturais e ambientais, além dos recursos financeiros, colaborando para uma alimentação saudável e uma qualidade de vida dos moradores do local. Dessa forma os saberes ambientais e culturais, que os quilombolas de Bailique criam e recriam, podem promover a autonomia e luta política para a libertação, de acordo com os moldes de educação, pensada por Paulo Freire (1993).

Observamos que os moradores quilombolas tentam refletir sobre as transformações sociais, culturais e ambientais e transmitem os saberes aos mais novos, assim, estes redescobrem o valor dos saberes tradicionais e das antigas práticas da comunidade. É nessa transmissão de saberes que acontece o processo de preservação das raízes quilombolas no Bailique Centro. Esses saberes são transmitidos por meio da oralidade, deixados pela ancestralidade, principalmente pelas pessoas mais idosas.

\section{Saberes Ambientais e práticas de resistências da Comunidade Quilombola de Bailique Centro, Oieiras do Pará}

O cotidiano na Comunidade Quilombola é permeado pelos saberes tradicionais, tanto pelo modo de ser e de viver das pessoas quanto também pelas relações existentes entre eles e o meio ambiente, nas atividades diárias, visto que, no atendimento às necessidades de sobrevivência, surgem os conhecimentos ecológicos, saberes e fazeres próprios da cultura da Comunidade.

A comunidade ainda conserva saberes e práticas importantes nos seus aspectos ecológicos, como: técnicas de adubação, restauração de igarapés, utilização de plantas medicinais etc., principalmente na forma de uso e preservação dos recursos naturais, uma vez que aprenderam a interagir com o ambiente em que vivem, num processo de saber local que, de acordo com Geertz (1997), é passado para as gerações futuras, oralmente ou por meio de observações do cotidiano.

Observamos na pesquisa que os quilombolas tentam refletir sobre as transformações sociais e culturais, acontecidas no Quilombo, e como transmitir 
os conhecimentos aos mais novos. Nessa situação, os mais novos descobriram atitudes que reafirmam o valor dos saberes tradicionais e das antigas práticas da comunidade. É nessa transmissão de saberes que se encontra a principal força positiva do processo de preservação das raízes quilombolas no Bailique, fortalecendo, dessa maneira, a cultural local. Esses modos de uso dos recursos naturais, por esse grupo quilombola, garantiu a sobrevivência sustentável da comunidade, visto que manteve e conservou a área da comunidade, além de manter também a sua riqueza cultural.

Segundo Cardoso (2002), os quilombos no Brasil representaram espaços de resistência de negros, índios e escravos brancos em geral. Nações e etnias diversas se assentaram nesses territórios, a maioria de origem africana. Os quilombos existiram não só no Brasil, mas em outros países da América Latina conhecidos como palanques ou chimarrões e remetiam a um lugar de encontro de nações, de resistência, contraponto da sociedade colonial. De acordo com Gomes (2009, p. 12):

Os quilombos representam as primeiras "aglomerações", formadas por escravos fugidos, durante o período colonial brasileiroll. Os quilombos em sua maioria eram agrícolas, mas alguns eram chamados de primeiras "cidades livres", onde exescravos negros, índios e brancos conviviam. Relembrando que o Brasil recebeu mais de 100 nações africanas diversas, além das nações indígenas aqui existentes e outras etnias europeias, a diversidade cultural dentro dos quilombos e entre quilombos é algo importante a se analisar.

Os quilombos, também denominados por Cardoso (2002) de núcleos populacionais de resistência de ex-escravos, existiram em todo o Brasil. Nos quilombos se constroem encontros e diálogos entre povos de cultura e simbologia diversas. Grupos étnicos indígenas, na diversidade de mais de 900 nações que aqui estavam antes do período colonial, uniram-se aos povos africanos. Mais de 100 etnias africanas diversas trazidas para o País associaram-se a esses grupos brasileiros e outros oprimidos - os europeus pobres - e traduziram no território usado a cultura possível: os quilombos, os primeiros povos livres e agroecológicos (CARDOSO, 2002).

A população quilombola não é homogênea no sentido étnico, muito menos do ponto de vista político-cultural, visto que os quilombos têm características e funções diversas em cada região. Logo, é necessário caracterizar os quilombos, sob o olhar de diferentes autores.

Moura (2004) observa que a palavra quilombo é de origem banta que, durante a escravidão no Brasil, significou ajuntamento de escravos fugidos e acrescenta que o primeiro quilombo, que se têm referências, data de 1573; refuta a teoria de que os quilombos no Brasil foram uma versão brasileira de 
estrutura homônima que floresceu em Angola nos séculos XVII e XVI que, para Roger Bastide (2001), é quase o início do tráfico negreiro.

Apesar de o termo quilombo ser um aportuguesamento da palavra kilombu, que em quimbundo significa arraial ou acampamento e coincidentemente as comunidades brasileiras de ex-escravos se organizavam sob a forma de acampamento, Moura (2004) não crê que seja possível a comprovação da hipótese da origem angolana das comunidades de escravos rebeldes. Para o autor, essa hipótese perde consistência, uma vez que se considera que os primeiros escravos africanos tinham a Guiné como procedência de origem e não Angola.

Os terreiros e quilombos também podem ser pensados enquanto comunidades negras principalmente para o movimento negro, como descreve Sodré (2006) em seus textos, ao se pensar num agrupamento humano, como o Quilombo dos Palmares, ou na organização litúrgica de um terreiro contemporâneo, surgindo a imagem da comunidade, isto é, indivíduos interdependentes por laços de sangue, etnia, território, religião ou projeto consensual. A produção dos saberes ambientais afro-brasileiro pode solicitar uma compreensão mais complexa do que a de Sodré (2006). O desafio que se apresenta passa por entender as formas que as medições adquirem dentro dos saberes ambientais desse possível projeto identitário, cujos processos de mediação são alguns dos elementos identificados e analisados neste estudo.

Portanto, os saberes e os fazeres dos remanescentes quilombolas vêm dialogando com a Educação Ambiental, a partir das "Histórias de Vida". Então, recuperar os conhecimentos como forma de saberes, construídos aos longos dos anos, é o que garante uma relação direta com o meio ambiente, permitindo manter um patrimônio natural e cultural nas comunidades quilombolas. Assim, os descendentes de quilombos têm a oportunidade de reconhecer a importância da questão ambiental, reparando os danos causados em seus territórios e criando responsabilidades a tal situação.

Pensar na Educação Ambiental nas comunidades tradicionais é conhecer a realidade dos sujeitos, compreender seus processos culturais, sua socialização e as relações de trabalho, vividas por esses sujeitos em suas práticas cotidianas. Nesse sentido, buscamos identificar e validar a identidade quilombola, avaliando os diferentes saberes e fazeres já construídos, a partir de suas histórias de vida.

$\mathrm{Na}$ Comunidade Quilombola de Bailique Centro, as terras dos moradores são denominadas quintais. A biodiversidade é comum no entorno da casa dos moradores. Possibilitam a convivência com plantas, pequenos animais e vida cultural. Festas de casamento, aniversários, rezas e batizados, pagodes, jogos de bola, e churrascos passam por ali, e os quintais com plantas e animais promovem trocas, processos de socialização e relações de vizinhança, que poucos imaginariam existir e resistir. 


\section{Conclusões}

Observamos que, no cotidiano da comunidade quilombola pesquisada, o ambiente local é dinâmico, diversificado e rico em conhecimentos de saberes tradicionais, notados pelos modos de ser e de viver dos moradores, das relações que eles têm com 0 meio ambiente, nas práticas diárias, principalmente no sentido do uso e da preservação dos recursos naturais, que são conhecimentos ecológicos desenvolvidos. É um dia a dia cheio de saberes e fazeres próprios da cultura da Comunidade.

Verificamos também que os conhecimentos sobre os saberes ambientais e culturais são transmitidos para os mais novos, assim eles têm a oportunidade de redescobrirem o valor dos saberes tradicionais e das práticas antigas da comunidade, dando a oportunidade dos mais velhos refletirem sobre as transformações sociais, culturais e ambientais. Dessa maneira, nessa transmissão de saberes, o processo de preservação das raízes quilombolas no Bailique são conservados.

Notamos que os saberes ambientais, desenvolvidos por intermédio de uma Educação Ambiental informal nas comunidades quilombolas, têm influenciado na preservação do meio ambiente principalmente da localidade pesquisada. E que esse saber está relacionado com a identidade e o conhecimento dos moradores, refletindo em seus valores e habilidades, possibilitando 0 aprendizado de novas técnicas do aprender-fazendo, ferramentas pedagógicas que podem auxiliar no desenvolvimento da Educação Ambiental em comunidades quilombolas.

Os dados demostram que os espaços de produção, as práticas, as roças, o processo de produção de farinha, o manejo da agricultura, o tempo de plantio e a colheita se configuram com práticas de resistências, onde são trabalhadas formas de organização social e a sociabilidade, sustentada pelos saberes culturais da comunidade, almejando, assim, a sustentabilidade e o desenvolvimento dos saberes ambientais.

Acrescentamos que as tradições, os valores e os conhecimentos são formas de saberes culturais que interferem positivamente nos modos de vida da comunidade. A dimensão cultural assume um sentido simbólico de representações de coisas e também um conjunto de práticas de resistências: social, política e cultural que orientam a construção dos espaços e a base econômica e ambiental. Portanto, a cultura aqui é vista como uma excelente maneira de orientar as formas de apropriação e uso dos recursos naturais, carregando em si uma potencialidade para construção e reconstrução das práticas e saberes das comunidades tradicionais.

Portanto, ao analisar o local em sua dimensão histórica, cultural e natural, verificando o grau de diversidade viva (natural e cultural) no contexto local e consideramos criticamente a construção da noção de pertencimento, os resultados apontaram as seguintes informações: 
- o saber ambiental está sendo desenvolvido pela maior parte dos moradores;

- muitos moradores conhecem, mas não compreendem a Educação Ambiental, atribuindo a esse termo somente a questão dos resíduos sólidos e a água;

- os jovens estão menos engajados e pouco se preocupam com a valorização ambiental;

- a maior parte dos moradores não desconhece o saber ambiental, embora os executem;

- todos os sujeitos da pesquisa contam que na comunidade não se contemplam essas questões, devido não existirem políticas públicas para a localidade.

- muitos moradores, principalmente os jovens, não executam a noção de pertencimento como as pessoas idosas;

- o ambiente é visto pela maioria dos moradores como o local de trabalho, onde pode ser desenvolvida a agricultura familiar que se torna a fonte de sobrevivência;

- existe um relacionamento de individualização e já se faz presente nas práticas de produção, nos mutirões em prol de áreas ecologicamente frágeis, e no pensamento do homem rural;

- por fim, a terra ou o ambiente é compreendido como espaço de trabalho, moradia, sobrevivência, convivência comunitária, pertencimento, relação com a natureza e de educação.

\section{Referências}

AMORIM, A. Educação. In: FERRARO JR., L. A. (org.). Encontros e caminhos: formação de educadoras (es) ambientais e coletivos educadores.Brasília: MMA, Diretoria de Educação Ambiental, 2005. p.143-147.

ARAUJO, R. M. de L. O marxismo e a pesquisa qualitativa como referências para investigação sobre educação profissional. In: ARAUJO, R. M. de L; RODRIGUES, D.do S. (org.). A pesquisa em trabalho, educação e políticas educacionais. Campinas: Alínea, 2012. p. 156-186.

BASTIDE, R. Candomblé da Bahia. São Paulo: Companhia das Letras, 2001.

BERGER FILHO, A. G.; SPAREMBERGER, R. F. L. Os direitos das populações tradicionais na ordem constitucional brasileira e sua relação com o acesso aos recursos genéticos. Revista Direito e Debate, ano XVI, n. 28, janjun 2008. 
CARDOSO, M. O movimento negro em Belo Horizonte 1978-1998. Belo Horizonte: Mazza Edições, 2002.

CHARLOT, B.; SILVA, V. A. Educação Ambiental: pesquisa e desafios. Porto Alegre: Artmed, 2005.

FREIRE, P. Educação como prática de liberdade. 14. ed. Rio de Janeiro: Paz e Terra, 1983.

GEERTZ, C. O saber local: novos ensaios em antropologia interpretativa. Petrópolis: Vozes, 1997.

GODOY, A. S. Introdução a pesquisa qualitativa e suas possibilidades. Revista de Administração de Empresas, São Paulo, v. 35, n. 2, p. 57-63, mar./ abr.1995.

GOMES, A. M. da S. Rotas e diálogos de saberes etnobotânica transatlântica negro africano: terreiros, quilombos, quintais da grande BH. 2009. 270f. Tese (Doutorado em Geografia) - Programa de Pós-Graduação em Geografia, Universidade Federal de Minas Gerais, Belo Horizonte, 2009.

INSTITUTO DE TERRAS DO PARÁ (ITERPA). Titulo de reconhecimento de domínio coletivo. Protocolo nº69.fls.04, livro 1-B. Oeiras do Pará: ITERPA, 2002.

LARAIA, R. de B. Cultura: um conceito antropológico. Rio de Janeiro: Zahar, 2009.

LEFF, H. Complejidad, Racionalidad Ambiental y Diálogo de Saberes: hacia una pedagogía ambiental. In: CONGRESSO IBEROAMERICANO DE EDUCAÇÃO AMBIENTAL, 5., 2006, Joinville. Anais eletrônicos [...]. Joinville: UFPR, $2006 . \quad$ Disponível em: $<$ https://eaterciario.files.wordpress.com/2015/09/conferencias-del-v-congresoiberamericano-de-educacion-ambiental-brasil-2006.pdf >. Acesso em: $16 \mathrm{dez}$. 2019.

LEFF, H. Epistemologia ambiental. 5. ed. São Paulo: Cortez, 2010.

LEFF, H. Saber ambiental: sustentabilidade, racionalidade, complexidade, poder. Tradução de Lúcia Mathilde Endlich Orth.Petrópolis: Vozes, 2001.

LOUREIRO, C. F. B. Trajetória e fundamentos da Educação Ambiental. São Paulo: Cortez, 2004.

MINISTÉRIO DO MEIO AMBIENTE (MMA). Convenção sobre a diversidade biológica, $1998 . \quad$ Disponível em: $<$ http://www.mma.gov.br/port/sbf/chm/doc/cdbport.pdf>. Acesso em: 4 maio 2015.

MOURA, C. Dicionário da escravidão negra no Brasil. São Paulo: EDUSP, 2004. 
MUNHÕZ, M. G. Saber indígena e meio ambiente: experiências de aprendizagem comunitária. In: LEFF, H. (coord.). A complexidade ambiental. São Paulo: Cortez, 2003. p. 111-131.

OLIVEIRA, H. H. de. Dança do congo: expressão, identidade e Educação Ambiental. 2011. 147 f. Dissertação (Mestrado em Educação) - Universidade Federal de Mato Grosso, Instituto de Educação, Cuiabá, 2011.

PINTO, B. C. de M. Filhas das matas: práticas e saberes de mulheres quilombolas na Amazônia Tocantina. Belém: Açaí, 2010.

SANTOS, B. S. A crítica da razão indolente: contra o desperdício da experiência. São Paulo: Cortez, 2008.

SHIVA, V. Monoculturas da mente: perspectivas da biodiversidade e biotecnologia. São Paulo: Gaia, 2003.

SODRÉ, M. Claros e escuros: identidade, povo e mídia no Brasil. Petrópolis: Vozes,2006.

TUAN, Y F. Topofilia: um estudo da percepção, atitudes e valores do meio ambiente. São Paulo: Difel, 1980. 